\title{
sciendo
}

\section{Periodontal Management during COVID-19 Pandemic: Mini Review}

\begin{abstract}
SUMMARY
A few cases of pneumonia were reported by Wuhan Municipal Health Commission in Wuhan, Hubei Province, Republic of China and this mysterious pneumonia was recognized as novel coronavirus disease (COVID-19) in the course of time on 31 December 2019. Based on the literature knowledge, COVID-19 outbreak was came into existence through an animal-to-human transmission, then continued human-tohuman diffusion. Especially dentists among the medical professionals are at high-risk group of SARS-CoV-2 virus contamination because of several routine dental procedures having the risk to convey the SARS-CoV-2 virus via droplets and close contact. In this mini review, it was aimed to give information about patient management during COVID-19 pandemic for dental practitioners, periodontologists and dental hygienists.
\end{abstract}

Key words: COVID-19, Dentistry, Periodontology, Periodontologists, Dental Hygienists

\author{
Sevda Kurt Bayrakdar' ${ }^{1}$, Betül Ilhan ${ }^{2}$ \\ Ibrahim Sevki Bayrakdar ${ }^{3}$, Funda Kurt \\ Alpay $^{4}$, Kaan Orhan 5 \\ ${ }^{1}$ Department of Periodontology, Faculty of \\ Dentistry, Eskişehir Osmangazi University, \\ Eskişehir, Turkey \\ ${ }^{2}$ Department of Oral and Maxillofacial \\ Radiology, Faculty of Dentistry, Ege University, \\ Izmir, Turkey \\ ${ }^{3}$ Department of Oral and Maxillofacial \\ Radiology, Faculty of Dentistry, Eskişehir \\ Osmangazi University, Eskişehir, Turkey \\ ${ }^{4}$ Internal Medicine Specialist, Rize State \\ Hospital, Rize, Turkey \\ ${ }^{5}$ Department of Oral and Maxillofacial \\ Radiology, Faculty of Dentistry, Ankara \\ University, Ankara, Turkey
}

REVIEW PAPER (RP)

Balk J Dent Med, 2021;135-138

\section{Introduction}

Due to rapid human-to-human transmission, the novel coronavirus raised one of the most crucial global health challenges that humankind has ever faced. The long and unpredictable incubation period (up to 27 days) of the virus further challenges infection control measures ${ }^{1}$. The novel coronavirus disease (COVID-19) caused by SARS-CoV-2 virus, present with non-specific symptoms such as fever, dry cough, shortness of breath, weakness, headache and diarrhea ${ }^{2,3}$. But having in mind that the rate of asymptomatic carriers is as high of $80 \%$, execution of strict isolation measures in dental settings is necesary ${ }^{4}$.

The aim of this paper is to highlight the importance of awareness of dental professionals who provide periodontal treatment about risks of SARS-CoV-2 airborn transmission and to make recommendations about periodontal approach during the pandemic era.

\section{Material and Methods}

This informative paper involved review of the current literature using PubMed and MEDLINE using following keywords: COVID-19, Dentistry, Periodontology. The literature search involved data published in English.

\section{Transmission of the virus}

The envelope spike (S) glycoproteins on the surface of SARS-CoV-2 interact with human angiotensin converting enzyme-2 (ACE-2) molecules and play a crucial role in invading the body. The expression of ACE-2 has also been reported on tongue, gingival epithelium and salivary gland, implementing oral cavity as a potential risk path for COVID-19 (similar to other ACE-2 expressing organs such as lungs) $)^{3,5}$.

The main routes for transmission of the virus are direct transmission through coughing, sneezing, and 
inhalation of droplets and contact transmission through contact with nasal, oral, and ocular mucosa. The presence of SARS-CoV-2 in blood, sputum and feces of infected patients and rare transmission by fecal-oral route has also been reported ${ }^{6,7}$. To et al detected SARS-CoV-2 in $91.7 \%$ of saliva samples from patients with COVID$19^{8}$. The presence of virus in saliva has been associated with 3 different pathways. In short, a) the exchange of liquid droplets between lower and upper respiratory track and oral cavity, b) the access of blood to oral cavity via crevicular fluid, and c) major- and minor-salivary gland infection, with subsequent release of particles in saliva via have been implied ${ }^{9}$.

\section{Preventing droplet transmission before dental treatment}

All dental professionals or dentists and dental hygienists who provide periodontal treatment are among the highest risk groups in terms of transmission of the disease through droplets and aerosols ${ }^{6,7,10,11}$. Ultrasonic scalers, piezotomes, hand tools, rotary instruments, air/water syringes, air polisher and lasers generate considerable amount of aerosols and increase the risk of cross-transmission between the professional and patient $^{6,10,12}$. Due to these risks, there have been countries around the world making new decisions for dental procedures. Several countries (e.g., California, USA) closed their dental facilities, some countries (e.g., UK) continued emergency dental treatments only; in addition, there were also countries that maintained regular dental treatments in this pandemic era ${ }^{13}$. The uncertainty of the patients' path to access to emergency care created an additional healthcare burden and increased the risk of contamination $^{13,14}$. In addition, the absence of a universal functioning has exhausted dental health professionals. What we know today on infection control during a pandemic bases on our experience gained from previous outbreaks of different coronaviruses and current data on SARS-CoV-2. In fact, in such pandemics, the ways to prevent transmission should be determined universally and in a way that does not differ by country.

All dental facilities should be obligated to adapt triage protocols including a detailed medical history and certain queries targeting to identify suspicious COVID19 cases. All patients should be considered as potentially asymptomatic. Necessary hygiene measures should be applied and minimal personal protective equipment (PPE) including long-sleeved disposable gown, disposable cap, surgical face masks, and protective eyewear should be used during the screening protocol ${ }^{7}$. The dental practitioner should question the patient and decide whether the complaint qualifies as a dental emergency ${ }^{6}$. The ADA recommends that dental practitioners should use their professional judgment to determine the need for urgent or emergency care $^{15,16}$. For initial interview, alternative strategies to minimize face-to-face contact such as telemedicine or tele-triage can be accomplished through internet or telephone. If the patient declares to have symptoms or a recent contact with a COVID19 patient during the interview, a pharmacologic pain and/or infection control agent may be prescribed if appropriate $^{6,17}$.

\section{Prevention of droplet transmission during dental treatment}

Caution should be given to surface cleaning ( $0.5 \%$ hypochlorite, for $1 \mathrm{~min})$ and sterilization of nondisposable items ${ }^{6,17,18}$. External mouth suctions, air purifiers and air exchangers have been evaluated for utilization in dental clinics ${ }^{19}$. It is recommended that dental treatments for COVID-19 patients and suspicious cases should be performed in negative pressure rooms/ chambers to prevent aerosol spread, however this may be a heavy economic burden for low and middle income countries and may not be fulfilled ${ }^{10,19}$.

The number of periodontal emergencies is limited and includes acute abscesses (e.g. periodontal or gingival abscess, endo-perio lesions), painful necrotizing conditions (i.e necrotizan ulcerative gingivitis and periodontitis, possible due to stress during pandemic), dentin hypersensitivity ${ }^{20}$ and oral lesions that decrease quality of life (e.g. painful ulcers, viral and fungal infections, cases required the biopsy). During these difficult times, pharmacological treatment is a safer option for these cases if applicable and appropriate. After initial examination, dental hygienists and periodontologists should consider debrimentation and maintenance treatments as non-emergency conditions (with the exception of specific and painful cases) and postpone all such elective procedures ${ }^{12,13}$. The efficacy of ultrasonic scalers have been found to be similar to manual instrumentation, but involve more risk in terms of aerosol spread ${ }^{10,21}$. It was reported that the amount of aerosols is regardless of the type of scaler and power level used and most of the droplets accumulate in inner corners of the eyes and around the nose $\mathrm{e}^{22,23}$. Therefore, if the patient's complaint qualifies as a dental emergency, manual scaling/polishing procedures should be preferred instead of ultrasonic instruments ${ }^{12}$. Mouth rinses with $0.2 \%$ povidone-iodine or $0.5-1 \%$ hydrogen peroxide are recommended before all of dental procedures to reduce the viral load in saliva. A history of allergy or thyroid disorders must be questioned before prescribing povidoneiodine rinses.

It should be remembered that oral rinses only reduce the amount of virus load in saliva and do not completely eliminate SARS-CoV-2 ${ }^{6,11}$. The effect of chlorhexidine, a commonly used compound in periodontology practice, against SARS-CoV-2 has not been demonstrated ${ }^{24}$. The development of more effective mouthwashes and rinses directly aiming to reduce SASR-CoV-2 load in oral cavity 
will facilitate dental treatments and provide a better means for infection control for our profession.

The selection of pharmacological agents should be made with caution. Although there are no comprehensive epidemiological studies demonstrating a possible adverse reaction of ibuprofen in COVID-19 patients, some controversy still exists in this regard ${ }^{25,26}$. In accordance with World Health Organization (WHO) reports, paracetamol can be used for pharmacologic pain control for dental pains as a first line treatment option. Patients should be advised not to self-medicate to relieve their pain and redundant drug use should be prevented. Telemedicine systems may also be effective during this process by direct communication with the patient for treatment planning ${ }^{7}$.

In case of aerosol generating procedures (such as using ultrasonic scalers, hand tools, air / water syringes), PPE such as aprons, masks, face shields and gloves should be used to protect the skin and mucous membranes from aerosol, and attention should be paid to hand hygiene. In such procedures, instead of surgical masks, N95 and N95 equivalent masks with more protective properties than surgical masks should be used ${ }^{27,28}$.

\section{Prevention of oral disease}

The periodontists, general dentists and dental hygienists who provide periodontal treatment should focus on oral hygiene training, emphasize the importance of maintaining good oral hygiene and raise awareness among the society on dental care during and after COVID-19 pandemic (through social media, telecommunication etc). This proposal has two main foundations: First of all, oral hygiene measures can reduce or control certain conditions that require emergency treatment and secondly periodontal health may have an influence on the course of COVID-19 ${ }^{24,29}$. Periodontal disease has been associated with an increased risk of several disorders such as cardiovascular diseases, diabetes and hypertension as well as bacterial pneumonia ${ }^{30-33}$. This suggests that periodontal disease may also be associated with COVID-19, even if we do not have detailed information on this issue at the moment.

\section{COVID-19 oral symptoms}

COVID-19 disease associated oral ulcer, oral herpes simplex-1, and vesiculobullous lesion have recently been reported ${ }^{34-36}$. Periodontologists should be aware of these lesions, as they may present as initial or proceeding symptoms of COVID-19. Additionally, Chloroquine, a commonly used agent for treatment of COVID-19, may cause melanotic pigmentation and lichenoid reaction in oral mucosa. Some post-identified and rare symptoms of COVID-19 include loss of taste and smell and may cause metallic taste and burning mouth syndrome ${ }^{37}$.

There is uncertainty on how long the pandemic era will last and what kind of measures will be taken in order to protect dental practitioners, stuff and patients during dental treatments. A possibility of a second wave spread has already been mentioned. It may be wise to assume that humankind will be living with SAR-CoV-2 and future pandemic threads longer than we first assumed. We still have much to learn and discover about the new COVID-19 disease and as dental professionals we must pay attention to oral disorders associated with the disease and inform dental society to protect our community and increase professional knowledge.

\section{Conclusions}

In conclusion, as of today SARS-CoV-2 virus and associated COVID-19 are not completely understood to their full extend. Their exact mechanism of action in human body and oral cavity remains to be solved. It is inevitable that a new era in dental profession will begin during normalization period and afterwards. This is informative paper on periodontal patient management during COVID-19 pandemic for dental practitioners, periodontologists and dental hygienists. We still need to review and revise our current practice of infection control and develop more strict protocols that will prevent nosocomial spread of infection during future pandemics. Furthermore, all dental professionals must follow recent reports and updates on the possible effect of COVID-19 on oral cavity, drug interactions and emerging of oral lesions associated with the disease and keep in mind that it is our obligation to protect ourselves, our patients and stuff while proving dental care during present and future pandemics.

\section{References}

1. Lai CC, Shih TP, Ko WC, Tang HJ, Hsueh PR. Severe acute respiratory syndrome coronavirus 2 (SARS-CoV-2) and corona virus disease-2019 (COVID-19): the epidemic and the challenges. Int J Antimicrob Agents, 2020;55:105924.

2. Wang C, Horby PW, Hayden FG, Gao GF. A novel coronavirus outbreak of global health concern. Lancet, 2020;395:470-473.

3. Xu H, Zhong L, Deng J, Peng J, Dan H, Zeng X, et al. High expression of ACE2 receptor of 2019-nCoV on the epithelial cells of oral mucosa. Int J Oral Sci, 2020;12:1-5.

4. Gralinski L, Menachery V. Return of the coronavirus: 2019nCoV. Viruses, 2020;12:135.

5. Zou X, Chen K, Zou J, Han P, Hao J, Han Z. Singlecell RNA-seq data analysis on the receptor ACE2 expression reveals the potential risk of different human organs vulnerable to $2019-\mathrm{nCoV}$ infection. Front Med, 2020:14;185-192.

6. Ather A, Patel B, Ruparel NB, Diogenes A, Hargreaves KM. Coronavirus disease 19 (COVID-19): implications for clinical dental care. J Endod, 2020:46;584-595. 
7. Lo Giudice R. The Severe Acute Respiratory Syndrome Coronavirus-2 (SARS CoV-2) in Dentistry. Management of Biological Risk in Dental Practice. Int J Environ Res Public Health, 2020;17:3067.

8. To KKW, Tsang OTY, Yip CCY, Chan KH, Wu TC, Chan JMC, et al. Consistent detection of 2019 novel coronavirus in saliva. Clin Infect Dis, 2020;71:841-843.

9. Sabino-Silva R, Jardim ACG, Siqueira WL. Coronavirus COVID-19 impacts to dentistry and potential salivary diagnosis. Clin Oral Investig, 2020:24;1619-1621.

10. Proffitt E. What will be the new normal for the dental industry? Br Dent J, 2020;228:678-680.

11. Spagnuolo G, De Vito D, Rengo S, Tatullo M. COVID-19 outbreak: an overview on dentistry. Int J Environ Res Public Health, 2020;17:2094.

12. Darwish S. COVID-19 Considerations in Dental Care. Dental Update, 2020;47:287-302.

13. Alharbi A, Alharbi S, Alqaidi S. Guidelines for dental care provision during the COVID-19 pandemic. Saudi Dent J, 2020;32:181-186.

14. Meng L, Hua F, Bian Z. Coronavirus disease 2019 (COVID19): emerging and future challenges for dental and oral medicine. J Dent Res, 2020;99:481-487.

15. Solana K, American Dental Association. ADA develops guidance on dental emer- gency, nonemergency care. 18 March 2020. https://www.ada.org/en/publications/adanews/2020-archive/march/ada-devel- ops-guidance-on-dentalemergency-none- mergency-care. Accessed 30 March 2020.

16. Abramovitz I, Palmon A, Levy D, Karabucak B, KotLimon N, Shay B, Kolokythas A, Almoznino G. Dental care during the coronavirus disease 2019 (COVID-19) outbreak: operatory considerations and clinical aspects. Quintessence Int, 2020;51(5):418-429.

17. de Almeida Geraldino R, Rezende LVMdL, da-Silva CQ, Almeida JCF. Remote diagnosis of traumatic dental injuries using digital photographs captured via a mobile phone. Dent Traumatol, 2017;33:350-357.

18. WHO. Cleaning and disinfection of environmental surfaces in the context of COVID-19. Interim guidance 15 May 2020. https://www.who.int/publications-detail/cleaning-anddisinfection-of-environmental-surfaces-inthe-context-ofcovid-19.

19. Halepas S, Ferneini EM. A Pinch of Prevention is Worth a Pound of Cure: Proactive Dentistry in the Wake of COVID19. J Oral Maxillofac Surg, 2020;78:860-861.

20. Jamal M, Shah M, Almarzooqi SH, et al. Overview of transnational recommendations for COVID-19 transmission control in dental care settings. Oral Dis, 2021;27:655-664.

21. Bouguezzi A, Cherni I, Sioud S, Hentati H, Selmi J. COVID-19: Special Precautions in Dentistry. OAJBS, 2020;2:ID.000164.

22. Nejatidanesh F, Khosravi Z, Goroohi H, Badrian H, Savabi O. Risk of contamination of different areas of dentist's face during dental practices. Int J Prev Med, 2013;4:611-615.

23. Harrel SK, Barnes JB, Rivera-Hidalgo F. Aerosol and splatter contamination from the operative site during ultrasonic scaling. J Am Dent Assoc, 1998;129:1241-1249.

24. Carrouel F, Conte MP, Fisher J, Souza Gonçalves L, Dussart C, Llodra JC, et al. COVID-19: A Recommendation to Examine the Effect of Mouthrinses with $\beta$-Cyclodextrin Combined with Citrox in Preventing Infection and Progression. J Clin Med, 2020;9:1126.
25. Day M. Covid-19: ibuprofen should not be used for managing symptoms, say doctors and scientists. BMJ, 2020;368:m1086.

26. Fang L, Karakiulakis G, Roth M. Are patients with hypertension and diabetes mellitus at increased risk for COVID-19 infection? Lancet Respir Med, 2020;8:e21.

27. ADA. Return to Work Interim Guidance Toolkit. https:// success.ada.org/ /media/CPS/Files/Open\%20Files/ADA Return_to_Work_Toolkit.pdf.

28. ADA. Interim Guidancefor Management of Emergency and Urgent Dental Care.https://www.coronavirus.kdheks. gov/DocumentCenter/View/853/ADA-Interim-Guidancefor-Management-of-Emergency-and-Urgent-Dental-CarePDF---4-15-20.

29. Berlin-Broner Y, Levin L. 'Dental Hierarchy of Needs' in the COVID-19 Era - or Why Treat When It Doesn't Hurt? Oral Health Prev Dent, 2020;18:95.

30. Taylor G. Periodontal health and systemic disorders. J Can Dent Assoc, 2002;68:188-192.

31. Nagaoka K, Yanagihara K, Morinaga Y, Nakamura S, Harada T, Hasegawa H, et al. Prevotella intermedia induces severe bacteremic pneumococcal pneumonia in mice with upregulated platelet-activating factor receptor expression. Infect Immu, 2014;82:587-593.

32. Lucia Macedo Paizan M, Fernando Vilela-Martin J. Is there an association between periodontitis and hypertension? Curr Cardiol Rev, 2014;10:355-361.

33. Scannapieco FA, Mylotte JM. Relationships between periodontal disease and bacterial pneumonia. JnPeriodontoL, 1996;67:1114-1122.

34. Martín Carreras-Presas C, Amaro Sánchez J, LópezSánchez AF, Jané-Salas E, Somacarrera Pérez ML. Oral vesiculobullous lesions associated with SARS-CoV-2 infection. Oral Dis, 2021;27:710-712.

35. Hedou M, Carsuzaa F, Chary E, Hainaut E, CazenaveRoblot F, Masson Regnault M. Comment on "Cutaneous manifestations in COVID-19: a first perspective" by Recalcati S. J Eur Acad Dermatol Venereol, 2020;35:e299-e300.

36. Chaux-Bodard A-G, Deneuve S, Desoutter A. Oral manifestation of Covid-19 as an inaugural symptom? Journal of Oral Medicine and Oral Surgery, 2020;26:18.

37. Odeh ND, Babkair H, Abu-Hammad S, Borzangy S, AbuHammad A, Abu-Hammad O. COVID-19: Present and Future Challenges for Dental Practice. Int J Environ Res Public Health, 2020;17:3151.

Conflict of Interests: Nothing to declare.

Financial Disclosu re Statement: Nothing to declare.

Human Rights Statement: None required.

Animal Rights Statement: None required.

Received on August 13, 2020.

Revised on February 8, 2021.

Accepted on March2, 2021.

\section{Correspondence:}

Sevda Kurt Bayrakdar

Department of Periodontology, Faculty of Dentistry

Eskisehir Osmangazi University, Turkey

e-mail:dt.sevdakurt@hotmail.com 